\title{
AS RELAÇÕES INTERPESSOAIS NA ENFERMAGEM: INFLUÊNCIA DA LIDERANÇA NA MOTIVAÇÃO DA EQUIPE TÉCNICA
}

\author{
INTERPERSONAL RELATIONSHIPS IN NURSING: \\ THE INFLUENCE OF LEADERSHIP ON MOTIVATION OF THE TECHNICAL TEAM
}

\author{
LAS RELACIONES INTERPERSONALES EN ENFERMERÍA: \\ LA INFLUENCIA DEL LIDERAZGO EN LA MOTIVACIÓN DEL EQUIPO TÉCNICO
}

\author{
Débora Silveira Novato ${ }^{1}$, Emanuelle Caires Dias Araújo Nunes²
}

\begin{abstract}
RESUMO
Introdução. A liderança em enfermagem é uma temática de crescente interesse, pela capacidade de influenciar os comportamentos de cuidado da equipe. Objetivos. Compreender a influência das relações interpessoais construídas pela liderança na motivação do técnico de enfermagem. Método. Trata-se de pesquisa descritivo-exploratória qualitativa, realizada em dois hospitais do interior da Bahia com oito técnicos de enfermagem por meio de entrevista semiestruturada, analisada mediante Discurso do Sujeito Coletivo. Resultados. Expressaram a importância do relacionamento interpessoal construído dentro da equipe para a motivação, a percepção dos técnicos de enfermagem sobre o estilo de liderança do enfermeiro e a existência de sentimentos motivacionais e desmotivacionais na equipe. Conclusão. As reflexões finais apontam para a necessidade de relações interpessoais vinculares dentro da Enfermagem, nas quais a condução esteja afinada com a Liderança Servil na perspectiva de valorização e motivação da equipe para o cuidado de si e do outro.
\end{abstract}

DESCRITORES: Relações Interpessoais; Equipe de Enfermagem; Liderança; Motivação.

\begin{abstract}
Introduction. Nursing leadership is a theme of increasing interest because of its ability to influence care behaviors of nursing staff. Objectives. The study aimed to understand the influence of interpersonal relationships built by the leadership on the motivation of the nursing technician. Method. This is a descriptive-exploratory qualitative research, carried out in two hospitals in the interior of Bahia, with eight nursing technicians through a semi-structured interview analyzed through the Discourse of the Collective Subject. Results. They expressed the importance of the interpersonal relationship built within the team for the motivation, the nursing technicians' perception about the nurse's leadership style and the existence of motivational and demotivational feelings in the team. Conclusion. The final reflections point to the need for binding interpersonal relationships within Nursing, in which the driving is in tune with the Servant Leadership in the perspective of valorization and motivation of the team to care for themselves and the other.
\end{abstract}

DESCRIPTORS: Interpersonal Relations; Nursing Team; Leadership; Motivation.

\section{RESUMEN}

Introducción. El liderazgo en enfermería es una temática de creciente interés por la capacidad que ella tiene de influenciar los comportamientos de cuidado del equipo. Objetivos. El estudio buscó comprender la influencia de las relaciones interpersonales construidas por el liderazgo en la motivación del técnico de enfermería. Método. Se trata de una investigación descriptiva-exploratoria cualitativa, realizada en dos hospitales del interior de Bahía con

1 Enfermeira pela Universidade Federal da Bahia, Campus Anísio Teixeira, IMS/CAT/UFBA. Pós-graduanda em Traumatologia pela Universidade Federal da Bahia, Campus Anísio Teixeira, IMS/CAT/UFBA. Enfermeira na Prefeitura Municipal de Tremedal (BA).

2 Professora Assistente da Universidade Federal da Bahia, Campus Anísio Teixeira, IMS/CAT/UFBA. Doutoranda do Programa Interunidades da Escola de Enfermagem da Universidade de São Paulo, EE-USP. 
ocho técnicos de enfermería a través de una entrevista semiestructurada analizada mediante el Discurso del Sujeto Colectivo. Resultados. Expresaron la importancia de la relación interpersonal construida dentro del equipo para la motivación, la percepción de los técnicos de enfermería sobre el estilo de liderazgo del enfermero y la existencia de sentimientos motivacionales y desmotivacionales en el equipo. Conclusión. Las reflexiones finales apuntan a la necesidad de relaciones interpersonales vinculantes dentro de la Enfermería, en las cuales la conducción está afinada con el Liderazgo Servil en la perspectiva de valorización y motivación del equipo para el cuidado de sí y del otro.

DESCRIPTORES: Relaciones Interpersonales; Grupo de enfermería; Liderazgo; Motivación.

\section{INTRODUÇÃO}

A escolha por esta temática começou enquanto cursava paralelamente as graduações de enfermagem e administração. Ao observar o quanto o comportamento do enfermeiro-líder influência nas ações da equipe técnica emergiram inquietações sobre a responsabilidade gerencial do enfermeiro em relação à equipe de enfermagem, na compreensão de que as relações construídas entre ambos contribuem para a qualidade de vida no trabalho e, consequentemente, para a motivação pela melhor assistência ao paciente.

Ao longo da história se pôde observar o quanto os recursos humanos foram renegados, surgindo apenas na década de 1920, o órgão ou setor que os administra, impulsionado pelos crescentes movimentos sindicais. Nessa época, o taylorismo era o modelo administrativo vigente e as pessoas eram vistas como recursos semelhantes ao capital, matéria-prima e máquinas. Inicialmente, esse novo setor estava voltado apenas para ações de bem-estar social, além de funções de recrutamento, questões salariais, aumento de produção e controle de pessoal. A principal preocupação do taylorismo era as questões salariais como meio motivacional, redução do desperdício e a separação de quem pensa e de quem faz. Foi somente depois dos estudos de Hawthorne, que houve uma mudança no pensamento e na forma de administrar o recurso humano ${ }^{1}$

A partir dos estudos de Elton Mayo, conhecidos como a experiência de Hawthorne se constatou que os seres humanos não podiam ser vistos como constantes, semelhantes a outros recursos utilizados na produção. Ele se propôs a estudar as condições que melhorariam o desempenho dos trabalhadores. Uma das fases do seu estudo, era relacionar a influência de fatores ambientais com a produção dos trabalhadores (como diferença de luminosidade e de níveis de ruídos). O que se percebeu foi que a diferença de iluminação ou de níveis de ruídos não diminuía a produtividade, mas que, fatores psico- lógicos, como a atenção dada às pessoas, a melhoria das relações pessoais e a valorização pessoal poderiam aumentar ou diminuir a produção².

No contexto da enfermagem também é necessário compreender o papel das pessoas ao longo do tempo, bem como o papel do líder Enfermeiro e dos liderados representados pela equipe de enfermagem, atentando para a construção de relações e para a importância do relacionamento interpessoal. Neste contexto, o enfermeiro acumula o papel de motivar e intermediar as relações na equipe. A valorização das relações interpessoais pela liderança contribui para melhora nos resultados esperados do trabalho, portanto, os relacionamentos devem ser pautados no respeito e na confiança, a partir da compreensão de que se trata de uma relação complexa, que envolve: comunicação verbal e não verbal, conflitos, recompensas e, principalmente, motivação. O líder tem responsabilidade direta sobre os relacionamentos estabelecidos entre seus liderados e, na enfermagem, cada vez mais se exige que habilidades de liderança sejam utilizadas pelo enfermeiro ${ }^{3}$.

Neste contexto, a motivação emerge como um fator primordial para que o trabalho em enfermagem aconteça, sendo sugerida pela teoria administrativa comportamental a sua influência no comportamento humano em âmbito profissional. Para isso, se utiliza da teoria dos dois fatores de Herzberg que infere que o trabalho é mais ou menos prazeroso a depender de dois fatores: os higiênicos, que englobam as condições de trabalho e os motivadores, que envolvem a necessidade de realização, de reconhecimento e de satisfação com o trabalho executado 4 .

Essa teoria é confirmada por afirmações, as quais apontam que o indivíduo tem que satisfazer suas necessidades em plenitude, visto que a motivação emerge das necessidades individuais, entre elas: ser aceito no grupo, ter prazer na tarefa executada, desenvolver mecanismos de recompensa, sentir reconhecimento profissional, poder ajudar o outro e interagir de forma saudável, entre outras necessidades igualmente desafiadoras ${ }^{5}$. Des- 
taca-se para isso o papel do enfermeiro que não deve se restringir aos cuidados ou gerência, mas também se dedicar em manter relações interpessoais terapêuticas, motivando os membros da equipe. Grande parte dos enfermeiros ainda baseia suas gerências nas escolas científicas e clássicas da administração, de modo que se faz importante que o enfermeiro se atualize quanto às estratégias e habilidades de motivação, pois esta pode ser uma ferramenta fundamental no desenvolvimento de potencialidades da equipe ${ }^{6}$.

Pois, para que o cuidado, objeto da práxis de enfermagem, seja efetivo é imprescindível que existam relações saudáveis e harmoniosas no ambiente de trabalho, além de uma gerência participativa, a fim de que o cuidador se mantenha motivado, cuidado e capaz de assistir adequadamente à necessidade do paciente, já que o trabalho na área da saúde é caracterizado por alto grau de tensão, sobrecarga de trabalho e o convívio com a dor e o sofrimento ${ }^{7}$.

Deste modo, a relevância deste estudo se mostra, para além da contextualização acima, nos achados da revisão de literatura, realizada a priori, que revelou escassez de estudos que articulem o relacionamento entre técnicos de enfermagem e o enfermeiro, enquanto líder, como fator de motivação, além de contribuir de maneira significativa para área do gerenciamento em enfermagem, elucidando como as relações interpessoais no ambiente profissional podem influenciar na motivação para o trabalho do técnico de enfermagem.

Assim, os questionamentos norteadores deste estudo foram: qual a importância das relações interpessoais entre enfermeiro e equipe de enfermagem? e, como a liderança influencia na motivação da equipe técnica?

\section{OBJETIVO}

Compreender a influência das relações interpessoais construídas pela liderança na motivação assistencial do técnico de enfermagem.

\section{MÉTODO}

Trata-se de um estudo descritivo, exploratório de abordagem qualitativa, que possibilita compreender de maneira detalhada e minuciosa o tema pesquisado, cujo cenário de pesquisa abrangeu as clínicas médicas e cirúrgicas de duas unidades hospitalares, uma privada e uma pública, no município de Vitória da Conquista, Bahia, bus- cando abranger cenários diferentes da assistência, com realidades distintas. Os sujeitos foram oito técnicos de Enfermagem, que compõem escala de serviço assistencial hospitalar, sendo quatro do sexo masculino e quatro do sexo feminino, com idades entre 26 e 40 anos, selecionados por meio dos critérios de inclusão: mais de um ano de profissão e mais de um vínculo empregatício atual em unidade hospitalar, buscando viabilizar a comparação entre as lideranças. $\mathrm{O}$ grupo de estudo foi delimitado pela saturação de dados, sendo suspensa a inclusão de novos participantes a partir do momento em que os discursos colhidos se tornaram redundantes

Os aspectos éticos que envolvem pesquisa com seres humanos foram respeitados conforme a Resolução 466/12, sendo a pesquisa aprovada sob Protocolo $n^{\circ} 306.672$ no Comitê de Ética em Pesquisa da Universidade Federal da Bahia - Instituto Multidisciplinar em Saúde/Campus Anísio Teixeira. Os dados foram coletados após assinatura do termo de consentimento livre e esclarecido durante um período de um mês, que teve por finalidade apresentar aos participantes os objetivos e métodos da pesquisa, bem como de garantir seu anonimato, imparcialidade e evitar prejuízo de qualquer natureza aos mesmos.

Foi realizada entrevista semiestruturada, durante período de trabalho dos técnicos, em local reservado do conforto de Enfermagem, sem a presença de outros profissionais, sendo a entrevista gravada, apenas com identificação numérica dos participantes e composta de duas fases. A primeira com questões gerais acerca do objeto de estudo (idade, sexo, tempo de serviço, tempo de formação, entre outras) e a segunda com questões específicas para a experiência em cada serviço, a qual era aplicada em dois momentos distintos e com foco em cada liderança por vez, oportunizando a comparação entre as vivências de ambas. A entrevista foi composta das seguintes questões: Fase 1: Como você compreende o papel do enfermeiro responsável pela equipe de enfermagem?; Quais habilidades/características este enfermeiro líder deve ter, em sua opinião? Qual a importância das relações interpessoais construídas entre vocês para o trabalho? O que você considera como condição ideal para desenvolver um cuidado de qualidade?

Fase 2: Escolha cinco sentimentos que predominam em relação ao estilo/tipo de liderança que você vivencia neste serviço; Que tipo de influência que a liderança do enfermeiro exerce sobre o seu trabalho? (Positiva ou Negativa) Por quê? Como você classificaria em uma palavra o estilo de liderança do enfermeiro (a) deste 
serviço? A entrevista foi realizada em local privativo na dependência das unidades de serviço durante o turno de trabalho dos técnicos, gravada em áudio e transcrita posteriormente.

A análise desenvolveu-se através da técnica do Discurso do Sujeito Coletivo, seguindo os passos: as questões foram analisadas de forma separada, identificando as expressões-chave centrais contidas nos discursos e as expressões-chave que ancoram o discurso do pesquisado, posteriormente, as ideias centrais e a ideias de ancoragem foram identificadas. Passada essa fase, a ideias centrais e de ancoragem foram agrupadas com outras que possuem o mesmo sentido, depois de agrupadas, os grupos foram denominados de acordo com a ideia central (IC) ou síntese da ancoragem, capaz de expressar o todo contido ali. Só então foi possível a construção do discurso do sujeito coletivo através da união de todas as expressões-chaves referentes a cada ideia central ou de ancoragem ${ }^{8}$.

\section{RESULTADOS}

A análise apontou três eixos resultantes da fala dos sujeitos. O primeiro eixo é sobre a influência das relações interpessoais na motivação do técnico de enfermagem, o segundo eixo sobre como a liderança influencia no trabalho do técnico de enfermagem e o terceiro eixo sobre o contexto em que surgem as relações e motivações na enfermagem.

Eixo 1: A influência das relações interpessoais na motivação do técnico de enfermagem-originou 3 IC. IC-A1: A IMPORTÂNCIA DO RELACIONAMENTO INTERPESSOAL ENTRE LÍDER E EQUIPE DE ENFERMAGEM

O relacionamento interpessoal é importantíssimo, ainda mais na Enfermagem que é tão desunida. Se ele existe, a gente consegue trabalhar em equipe, porque tem uma melhor convivência, facilita a comunicação, gera respeito e faz com que a equipe tenha uma boa conexão. O trabalho fica mais fácil quando você tem uma relação amigável com o enfermeiro, ele passa a sentir segurança em você, ensinando e tirando as dúvidas para desenvolver um cuidado de qualidade, firmando uma relação de ajuda mútua, ajudando e sendo ajudado para que o trabalho aconteça sem confusão (DSC-A1).

\section{IC-B1: SENTIMENTOS RELACIONAIS PROMOTORES} DE MOTIVAÇÃO NA EQUIPE DE ENFERMAGEM
O trabalho na Enfermagem tem muito cooperativismo, união da equipe, a gente tem alegria e satisfação em trabalhar na saúde, além disso, criamos laços de amizade e respeito, isso aumenta a qualidade do cuidado. Você acaba formando uma família no trabalho, o enfermeiro é seu companheiro, essa relação amigável ajuda muito no desenvolvimento das atividades. É importante que você se coloque no lugar do outro, isso cria uma motivação para o trabalho, além de dar mais confiança e autonomia. Na Enfermagem, a gente tem que amar o que faz, a gente fica mais humano e cuida melhor, pois desenvolvemos a solidariedade, o cuidar do outro que traz satisfação (DSC-B1).

\section{IC-C1: SENTIMENTOS DESMOTIVACIONAIS EMER- GENTES DE RELAÇÕES CONFLITUOSAS NA EN- FERMAGEM}

A Enfermagem é cheia de desunião, isso me causa indignação e raiva. Falta reivindicação da classe! Me entristece ver tanta submissão, tanta cobrança, incompreensão, desvalorização e autoritarismo com o técnico de enfermagem. Toda essa situação gera desânimo, um sentimento de impotência e desrespeito, além do estresse, pois nos sentimos discriminados porque não somos formados, o enfermeiro estudou mais do que nós, então quem fica na execução das tarefas são os técnicos (DSC-C1).

Eixo 2: A liderança como fator de influência no trabalho do técnico de enfermagem- originou 3 IC.

\section{IC-A2: LIDERANÇA MOTIVACIONAL}

O enfermeiro é um líder necessário dentro da equipe que tem o poder de motivar o técnico de enfermagem se for competente, humilde, compreensivo, amigo e exigente, mas sem ser autoritário. Sua função é de direcionar a equipe, delegando o que cabe a cada um, gerenciando a assistência ao paciente e garantindo suporte à equipe. Para isso, precisa ter compromisso, seriedade, responsabilidade, iniciativa, visão ampla e ser empreendedor, priorizando a qualidade do serviço para que conquiste o respeito da equipe, tornando-se um exemplo a ser seguido. E, em relação à equipe tem que saber ouvir, ter jogo de cintura, ser prestativo, flexível, tratar todos de forma igual, saber falar no momento certo e também saber escutar críticas (DSC-A2).

\section{IC-B2: LIDERANÇA DESMOTIVACIONAL}

O enfermeiro chefe desmotiva, têm atitudes autoritárias e ofensivas, o que dificulta o relacionamento 
dentro da equipe, ele dá as ordens e tem que ver se a gente fez tudo certinho, eles deveriam se ocupar de atividades mais complexas com o paciente, saber de tudo e sobre todos, mas só ficam na administração, muitos não sabem cuidar, só sabem mandar, exigem muito do técnico e se tornam incompreensivos, se eu não fizer o que tenho que fazer ele me pede explicações (DSC-B2).

\section{IC-C2: ANCORAGEM: O BOM LÍDER TEM QUE “SAB- ER FAZER"}

Antes de ser coordenador o enfermeiro deve saber fazer as técnicas de uma forma correta, tem que saber puncionar bem um acesso venoso, saber fazer uma passagem de sonda vesical, entender um ECG, ter visão crítica e sensível às alterações clínicas, saber argumentar com os médicos, ter conhecimento das mais diversas patologias, alterações, sintomas, tratamento e diagnóstico. Um bom enfermeiro é aquele que alia o conhecimento teórico com a prática, pois ele tem que ter um conhecimento vasto, tem que ser bom, inteligente, tem que saber fazer de tudo com segurança e é importante que ele ajude na execução do serviço diário (DSC-C2).

Eixo 3: O contexto em que surgem as relações e motivações na enfermagem - originou 2 IC.

\section{IC-A3: AS PEDRAS DO CAMINHO: DESAFIOS DIÁRI-} OS NA CONTRAMÃO DA MOTIVAÇÃO

Não tem como prestar um cuidado de qualidade com uma enorme quantidade de pacientes, a demanda é grande, o salário é ruim o que faz com que eu tenha que ter mais vínculos empregatícios. Tem dia que falta material, até luva já faltou, somos obrigados a fazer "armengações", o trabalho é cansativo e difícil, além disso, tem o enfermeiro que sempre cobra mais do técnico de enfermagem, no emprego particular cobra mais ainda (DSC-A3).

\section{IC-B3: AS FLORES DO CAMINHO: UM CONTEXTO PROPÍCIO À MOTIVAÇÃO}

O trabalho para a execução de um cuidado ideal tem que ter material suficiente, uma equipe boa de tamanho, boa de conhecimento e comprometida, estrutura física de qualidade, além disso, a escala tem que ser flexível, isso me deixa mais tranquila. No emprego particular é melhor porque a estrutura é boa, tem muita capacitação, poucos pacientes e muita organização, o enfermeiro aqui acaba ajudando também a manter tudo em ordem e organizado, além disso, tem um bom relacionamento com todos (DSC-B3).

\section{DISCUSSÃo}

O primeiro eixo apresentou discursos antagônicos que envolveram duas temáticas: os que estão envoltos em sentimentos causadores de motivação e os que possuem sentimentos desmotivadores. Além disso, o DSC-a1 chama a atenção para o bom relacionamento interpessoal como fator motivador dentro da equipe de enfermagem.

Observou-se que muitos técnicos de enfermagem possuem sentimentos desmotivacionais que surgem a partir de situações de conflito, relação interpessoal ineficaz, relações de poder, sobrecarga de trabalho, falta de apoio, desvalorização profissional ${ }^{7}$, em que a maioria dos técnicos se encontra, o que influencia nas relações interpessoais construídas entre a equipe, favorecendo a ocorrência de conflitos e reforçando o círculo vicioso da desmotivação ${ }^{6}$.

Por outro lado, os sentimentos causadores de motivação também existem e devem ser reforçados pelo enfermeiro-líder dentro do relacionamento construído pela equipe. O enfermeiro é visto como um líder que ajuda na aproximação da equipe, partilha conhecimentos, cria um ambiente de confiança e laços entre as pessoas, possuindo a capacidade de interferir para facilitar e aperfeiçoar as relações, causando motivação, gerando colaboração dos liderados, o que faz de maneira informal e formal, sendo constatado que para liderar sua equipe o enfermeiro deve ter atitudes inovadoras. A união de todos da equipe foi vista como característica positiva para que exista ambiente motivador e de alta qualidade profissional $^{9}$.

Não se pode esquecer que a motivação está diretamente ligada a bons relacionamentos, o que não envolve somente comunicação verbal, mas também, demonstração de sentimentos, empatia, troca de experiência, entre outras manifestações que não possuem, em nada, simplicidade $^{2}$. Um bom relacionamento interpessoal é uma ferramenta de liderança bastante desejada, e pode ser considerado como a capacidade de trabalhar em equipe com cooperação e respeito, capacidade que pode ser aprendida ou desenvolvida e é uma característica muita procurada dentro das organizações ${ }^{10}$.

Essa compreensão remete à importância do enfermeiro enquanto líder assumir o papel de mediador no gerenciamento de conflitos, habilidade que requer postura de facilitador e não de controlador, construindo relações de confiança ${ }^{11}$. De modo que o relacionamento interpessoal no ambiente profissional deve ser 
trabalhado, principalmente, entre líder e liderados para influenciar na qualidade das atividades desenvolvidas, já que a precariedade nas relações pode causar diminuição da motivação para o trabalho e da qualidade da assistência prestada ${ }^{9}$.

É neste contexto de mediador que entra o enfermeiro e a liderança que deve ser exercida por ele, a fim, de fortalecer os relacionamentos e aperfeiçoar o trabalho em grupo. O enfermeiro precisa estar apto a lidar consigo e com os demais membros da equipe, para que todos sejam motivados com uma liderança baseada na confiança, no respeito mútuo e na valorização profissional.

O segundo eixo destacou o papel do líder como incentivador ou não do trabalho realizado pelo técnico de enfermagem, além de trazer como reforço uma ideia de ancoragem que se perpetua que é a de que para mandar tem que saber fazer.

Acerca desta, se infere que é reconhecida a necessidade do líder ter conhecimento técnico-cientifico e habilidade prática. O enfermeiro ainda é visto como um profissional que tem sua atuação direcionada a um saber técnico e mecanicista. A equipe de enfermagem enxerga na figura do enfermeiro alguém que tem que saber todas as técnicas e, além disso, tem que as realizar, mesmo que apenas nos pacientes com maior gravidade. Portanto, a visibilidade do enfermeiro ainda está voltada ao fazer técnico ${ }^{12}$. Mas observa-se nas entrelinhas desta ancoragem uma queixa que visa, na verdade, denunciar a falta de um relacionamento positivo de humildade e ajuda mútua entre o líder e a equipe de enfermagem.

Isso existe porque não há um único estilo de liderança, já que os mesmos variam de acordo com as relações, contexto e situações diárias. Surgem deste fato as diferentes formas em que o líder é visto por seus liderados, o chefe versus o líder ${ }^{13}$. A forma de liderar e o estilo do líder interferem na forma como o grupo se relaciona e na motivação para o trabalho, pois se acredita que o grupo se espelha no seu líder. O enfermeiro que se assume como líder se relaciona melhor com os membros da equipe, ocorrendo maior motivação e satisfação no ambiente de trabalho ${ }^{14}$, podendo ajudar, do contrário o chefe vem atrapalhar, já que as relações de trabalho e poder podem criar um afastamento na equipe ${ }^{15}$.

Deste modo, o bom líder tem o desafio de desenvolver uma gerência adequada dos recursos humanos voltada para tomada de decisão e resolução de conflitos, isso é o que sugere a liderança dialógica, onde há um equilíbrio entre o alcance da produtividade e o bom re- lacionamento, com foco nas pessoas, levando em conta suas necessidades, personalidades e anseios, garantindo o alcance de melhores resultados. Neste contexto, é necessário que o enfermeiro esteja consciente da importância das pessoas e, principalmente, do trabalho em grupo, evitando o modelo de gestão autocrática. É viável, portanto, que este exerça uma liderança pautada na responsabilidade incorruptível, através do estabelecimento de laços de confiança, diálogo e de conhecimento ${ }^{16}$.

$\mathrm{Na}$ contramão do líder está a figura do chefe, que tem suas atitudes pautadas na verticalização de ordens, centralização do poder, foco na produtividade, além da sobrecarga de trabalho dentro da equipe, comportamento observado dentro da teoria clássica, que trata os recursos humanos como máquinas, em um ambiente que contribui para que as relações sejam tensas e precárias ${ }^{17}$.

Diante disso, o que se espera do enfermeiro é que ele exerça o papel de líder na coordenação da sua equipe. Para isto, é necessário, o desenvolvimento de várias habilidades, como a capacidade de motivar sua equipe, desenvolver relações de confiança, de resolver possíveis conflitos, administração eficiente de pessoal, entre outras, levando em conta a necessidade individual, e que abranja também o bom desempenho da função assistencial ${ }^{18}$. De modo que, se relacionar no ambiente de trabalho em enfermagem requer ir além das especificações técnicas da profissão, pautando as ações de saúde no respeito, ajuda, criação de vínculos, comunicação interpessoal, sensibilidade e valorização pessoal capazes de estimular o trabalho em equipe ${ }^{9}$.

Portanto, a liderança emerge como o ato de exercer influência sobre o outro, a fim de que o outro faça aquilo que se deseja, em prol de um bem comum, mas de forma distante do autoritarismo, pois o líder em primeiro lugar deve ter humildade, deve buscar a verdadeira necessidade de seus liderados, sendo o dirigente que ele mesmo gostaria de ter. A liderança servil influencia as pessoas com entusiasmo no trabaIho, além de desenvolver empatia e comportamentos de amor, se colocando no lugar do outro e agindo em prol do bem do próximo ${ }^{19}$.

Mas o líder precisa possuir diversas habilidades e características para que consiga exercer o seu papel de maneira agradável e eficiente. A grande questão é balancear os estilos de liderança em todo o tempo, indo além da proposta contingencial ao fundir os estilos num perfil diferenciado. Portanto, se faz necessário que o líder encontre o seu ponto de equilíbrio, sabendo que 
papel exercer e quando exercer para que o bem comum seja alcançado, deixando de lado falsas necessidades, baseadas na individualidade. Desta forma, os obstáculos diários devem ser enfrentados em equipe, buscando valorizar o que cada um tem de melhor e incentivando as potencialidades para o alcance dos resultados.

O trabalho realizado por técnicos de enfermagem é permeado por dificuldades. Não é fácil o convívio com dor e morte, somado à desvalorização profissional e conflitos internos. Porém, não se pode negar que quando o alcance dos resultados é obtido a alegria e satisfação que gera é capaz de superar as dificuldades. Esses resultados foram apontados no terceiro eixo. Sentir a gratidão do outro ou ainda saber que toda a sua capacidade foi utilizada para fazer o bem é muito mais recompensador do que os percalços encontrados.

O terceiro eixo evidencia as fragilidades e as potencialidades que envolvem o trabalho realizado pelos técnicos de Enfermagem. O trabalho diário é, por muitas vezes, desgastante, tanto do ponto de vista físico-corpóreo, como do ponto de vista sentimental. As jornadas e plantões, a falta de material e estrutura adequada, além do convívio diário sofrimento alheio, fazem com que o cuidador tenha uma enorme necessidade de cuidado. Por isso, o ambiente profissional deve promover a saúde do trabalhador, incentivando para que o cuidador também seja cuidado ${ }^{20}$.

A atuação em um ambiente que provê estrutura física de qualidade, materiais suficientes, qualificação profissional, escalas justas, quantidade correta de pacientes, planos de cargos e salários, além do apoio psicológico e afetivo, favorece para que o profissional não se sinta frustrado em relação a si, ao seu trabalho e aos demais colegas, criando um ambiente de trabalho que preserva a saúde do trabalhador. Também é preciso que os gestores desenvolvam condições que assegure a satisfação no trabalho e a garantia dos direitos do trabalhador, o que gera motivação e melhor qualidade de vida no ambiente profissional ${ }^{21}$.

É baseado nesse aspecto de respeito e condições favoráveis de trabalho que se pode afirmar que, apesar de tudo, o trabalho em Enfermagem pode ser satisfatório. Para isso é necessário que haja a correta superação dos problemas, identificando o que o pode ter ocasionado e evitando novos conflitos desnecessários. A comunicação deve ser incentivada de forma respeitosa e clara, as relações interpessoais devem ser estreitadas promovendo a ajuda, solidariedade e união da equipe. $O$ líder tem papel primordial em garantir que as condi- ções de trabalho sejam adequadas, buscando a melhor qualidade de vida para o trabalhador, portanto, o líder deve ser amigável, estimulando a crítica construtiva e a valorização pessoal ${ }^{12}$.

É com base nesses preceitos que as barreiras diárias podem ser vencidas, facilitando o convívio entre os membros da equipe, garantindo motivação para a realização do trabalho e a preservação do cuidador ${ }^{20}$. Diante da discussão acima, se observa a complexidade das relações interpessoais que envolvem a gerência em enfermagem, ao tempo em que sobram evidências da sua importância para o trabalho em equipe, a satisfação pessoal e a saúde do trabalhador.

Hoje, a administração eficiente dos recursos humanos, baseado em uma liderança democrática é de fundamental necessidade dentro da enfermagem. As necessidades dos técnicos de enfermagem devem ser levadas em consideração, a motivação deve ser algo continuamente buscado dentro da Enfermagem, favorecendo assim uma maior realização pessoal e profissional. Os problemas são muitos, mas as estratégias de superação devem ser traçadas e colocadas em prática. É neste contexto ambíguo que, o líder em Enfermagem deve atuar, para garantir que a integralidade da equipe não seja abalada, mesmo diante das situações adversas, a fim de que trabalhem em prol do bem comum, que é o cuidado de si e do outro.

\section{CONSIDERAÇÕES FINAIS}

O objetivo de compreender as influências das relações interpessoais construídas pela liderança na motivação assistencial do técnico de enfermagem foi alcançado, mostrando que os técnicos são influenciados pelo estilo de liderança, podendo este exercer motivação ou desmotivação no trabalho desenvolvido. Os resultados encontrados apontam para a fragilidade nas relações interpessoais construídas, ao tempo em que demonstram que o relacionamento se faz imprescindível dentro da Enfermagem. A equipe técnica se encontra desmotivada quanto às condições de trabalho, mas, apesar da desmotivação, consegue enxergar as potencialidades da profissão, o que abre uma possibilidade compensatória a ser trabalhada no grupo.

Este estudo evidenciou a importância do papel do enfermeiro-líder, que pode influenciar na motivação da equipe, na medida em que é capaz de garantir a satisfação das genuínas necessidades do grupo visando à preservação de sua integridade para alcance de uma 
liderança e cuidado ideais, requerem esforço e perseverança, mas que não são impossíveis de serem alcançados, principalmente quando existe amor ao que se faz e para quem se faz. O vínculo empático entre o líder e sua equipe potencializa a motivação frente aos obstáculos do cotidiano de cuidados de enfermagem, promove a coesão e afinidade nos comportamentos da equipe e desperta para a internalização de uma filosofia de cuidado que parte da liderança e expressa humanidade, atenção, interesse e empenho em acolher e organizar a equipe através da construção de relacionamentos saudáveis e comprometidos com o respeito, a aceitação e o amor ao próximo.

Desse modo, o enfermeiro possui grande responsabilidade na motivação ou desmotivação da equipe de enfermagem, além do que, laços de amizade criados dentro do ambiente profissional favorecem o cuidado de si e do próximo, devendo a liderança, para isso estar atenta aos sinais de alerta que indicam desmotivação e precariedade das relações, como comunicação prejudicada, conflitos internos e desânimo, visando intervenções positivas. Nesse sentido, propõe-se que o enfermeiro dedique mais tempo para ouvir as demandas da equipe, procurando construir uma liderança participativa e servidora, com comunicação fluente e minimização de conflitos. Sugere-se também que técnicas de motivação sejam estudadas e utilizadas no ambiente de trabalho para melhorar a qualidade de vida do trabalhador e, consequentemente, sua assistência prestada ao paciente.

Esta pesquisa revelou limitações referentes ao restrito contexto do grupo de participantes, o que desperta para o desafio de novas pesquisas na área capazes de ampliar as percepções da equipe em relação à liderança dos enfermeiros. 


\section{REFERÊNCIAS}

1. Rodrigues EA. Teorias da administração. Londrina: Editora e Distribuidora Educacional S. A.; 2016.

2.Fernandes RMD, Alencar LCQ de. Coaching ou uma releitura das teorias administrativas: teoria das relações humanas e teorias da motivação. [Bacharelado em Administração]. Fortaleza: Faculdade Cearense; 2014.

3. Lima EC, Bernardes A, Baldo PL, Mazlero VG, Camelo SHH, Balsanelli AP. Critical incidents connected to nurses' leadership in Intensive Care Units. Rev Bras Enferm. 2017; 70(5):1018-1025.

4. Lacombe FJM, Heilborn GLJ. Administração: princípios e tendências. $3^{\text {a }}$ ed. São Paulo: Saraiva; 2016.

5. Somense CB, Duran ECM. Fatores higiênicos e motivacionais do trabalho do enfermeiro em enfermaria de cardiologia. Rev. Gaúcha Enferm. 2014; 35(3):82-89.

6. Bezerra FD, Andrade MFC, Andrade JS de, Vieira MJ, Pimentel D. Motivação da equipe e estratégias motivacionais adotadas pelo enfermeiro. Rev Bras Enferm. 2010; 63(1):33-37.

7. Abreu RMD de, Gonçalves RMDA, Simões ALA. Motivos atribuídos por profissionais de uma Unidade de Terapia Intensiva para ausência no trabalho. Rev Bras Enferm. 2014; 67(3):386-393.

8. Lefèvre $F$, Lefèvre AMC. O discurso do sujeito coletivo: um novo enfoque em pesquisa qualitativa (desdobramento). $2^{\mathrm{a}}$ ed. Caxias do Sul: Educs; 2005.

9. Silva VLS, Camelo SHH, Soares MI, Resck ZMR, Chaves LDP, Santos FC dos, et al. Leadership practices in hospital nursing: a self of manager nurses. Rev Esc Enferm USP. 2016;51:1-8.

10. Silveira CD, Bessa ATT de, Paes GO, Stipp MAC. Géstiondel equipo de enfermaria: factores associados a La satisfacción em eltrabajo. Enferm Global. 2017; 16(47):208-223.

11.Vendemiatti M, Siqueira ES, Filardi F, Binotto E, Simioni FJ. Conflito na gestão hospitalar: o papel da liderança. Ciênc Saúde Colet. 2010; 15 Suppl 1:1301-1314.
12. Backes DS, Backes MS, Sousa FGM de, Erdmann AL. O papel do enfermeiro no contexto hospitalar: a visão de profissionais de saúde. Cienc Cuid Saude. 2008; 7(3):319-326.

13. Barbosa AL. A arte de liderar: o papel do líder na gestão de conflitos. [Bacharelado em Administração]. Igarassu: Faculdade de Teologia Integrada; 2015.

14. Santos I dos, Castro CB. Estilos e dimensões da liderança: iniciativa e investigação no cotidiano do trabaIho de enfermagem hospitalar. Texto Contexto Enferm. 2008; 17(4):734-742.

15. Waldow VR. O cuidado na saúde: as relações entre o eu, o outro e o cosmos. Petrópolis: Vozes; 2004.

16. Amestoy SC, Oliveira AFL de, Thofehrn MB, Trindade LL, Santos BP dos, Bao ACP. Contribuições freirianas para entender o exercício da liderança dialógica dos enfermeiros no ambiente hospitalar. Rev Gaúcha Enferm. 2017; 38(1):e64764

17. Marquis BL, Huston CJ. Administração e liderança em enfermagem: teoria e prática. $6^{\mathbf{a}}$ ed. Porto Alegre: Artmed; 2015.

18. Yañez - Gallardo RJ, Valenzuela - Suazo S. Conductas críticas para experimentar confianza em elliderazgo em enfermería em un hospital de alta complejidad. Aquichan. 2013; 13(2):186-196.

19. Hunter JC. De volta ao mosteiro: o monge e o executivo falam de liderança e trabalho em equipe. Rio de Janeiro: Sextante; 2014.

20.Garcia TR, Cabral IE. Notas sobre enfermagem: um guia para cuidadores na atualidade. Rio de Janeiro: Elsevier; 2010.

21. Ferro D, Zacharias FCM, Fabriz LA, Schonholzer TE, Valente SH, Barbosa SM, et al. Absenteísmo na equipe de enfermagem em serviços de emergência: implicações na assistência. Acta paul enferm. 2018; 31(4):399-408. 